\title{
The transcription factor Snf1p is involved in a Tup1p-independent manner in the glucose regulation of the major methanol metabolism genes of Hansenula polymorpha
}

\author{
Marcos A. Oliveira ${ }^{1}$, Victor Genu ${ }^{1}$, Anita P.T. Salmazo ${ }^{1}$, Dirce M. Carraro ${ }^{2}$ and Gonçalo A.G. Pereira ${ }^{1}$ \\ ${ }^{1}$ Universidade Estadual de Campinas, Instituto de Biologia, Departamento de Genética e Evolução, \\ Laboratório de Genômica e Expressão, Campinas, SP, Brazil. \\ ${ }^{2}$ Ludwig Institute for Cancer Research, São Paulo, SP, Brazil.
}

\begin{abstract}
Hansenula polymorpha is a methylotrophic yeast widely employed in biotechnology as a "protein factory". Most promoters used for heterologous protein expression, like MOX (methanol oxidase) and DAS (di-hydroxy acetone synthase), are involved in the peroxisomal methanol metabolism $\left(\mathrm{C}_{1}\right.$ metabolism) and are under strong glucose repression. Interestingly, the MOX promoter is subjected to glucose regulation also in Saccharomyces cerevisiae, a non-methylotrophic yeast in which this phenomenon is well studied. In this species, the transcription factor Tup1p plays an essential role in glucose repression of several genes. This effect is counteracted by the activator Snf1p when glucose is exhausted from medium. Therefore, to test whether this regulatory circuit has been conserved in $H$. polymorpha, HpTUP1 and HpSNF1 were partially cloned and disrupted. Deletion of HpTUP1 did not affect glucose repression of the major $\mathrm{C}_{1}$ metabolism genes $(M O X, D A S)$. Thus, though conserved, HpTUP1 does not seem to take part in a general glucose repression in $H$. polymorpha. In contrast, the deletion of HpSNF1 led to significant decreases in the activation of these genes in the absence of glucose. Therefore, the effect of HpSNF1 in transcriptional activation may be through an HpTUP1- independent circuit.
\end{abstract}

Key words: TUP1, SNF1, Hansenula polymorpha, glucose repression, MOX.

Received: October 14, 2002; Accepted: August 15, 2003.

\section{Introduction}

Hansenula polymorpha (syn. Pichia angusta) belongs to a limited group of yeast capable of using methanol as the sole carbon and energy source (Veenhuis et al., 1983). The expression of the major enzymes accounting for peroxisomal methanol metabolism $\left(\mathrm{C}_{1}\right.$ metabolism $)$, namely methanol oxidase (Moxp), catalase (Catp) and di-hydroxi acetone synthase (Dasp), is controlled at the transcriptional level. The genes encoding these three enzymes are fully induced when cells are grown on methanol, and repressed to different extents in the presence of glucose (Genu et al., 2003; Janowicz et al., 1985; Roggenkamp et al., 1984). For instance, Moxp can represent up to $30 \%$ of the total soluble cellular proteins in continuous cultures growing on methanol (Giuseppin et al., 1998). In the presence of glucose, however, no methanol oxidase activity can be detected in crude extracts (Veenhuis et al., 1989). In view of this, the $M O X$ promoter has been widely employed

Send correspondence to Gonçalo A.G. Pereira. Universidade Estadual de Campinas, Instituto de Biologia, Departamento de Genética e Evolução, Laboratório de Genômica e Expressão, 13083-970 Campinas, SP, Brazil. E-mail: goncalo@ unicamp.br. for heterologous protein expression, and H. polymorpha has been considered a "versatile protein factory" (Gellissen, 2000; van Dijk et al., 2000). Nevertheless, although it is a very suitable source of carbon for general industrial fermentation, glucose cannot be regularly employed for protein expression in $H$. polymorpha. It would therefore be a significant technological improvement if the $M O X$ promoter could also function in glucose-containing media.

The MOX promoter has been studied in detail. Promoter mapping has revealed four $c i s$-acting regulatory elements (Godecke et al., 1994), but no H. polymorpha factor directly involved in $M O X$ regulation has been identified to date. Remarkably, the $M O X$ promoter can drive glucose-repressible expression of a reporter gene in Saccharomyces cerevisiae (Pereira and Hollenberg, 1996), a non-methylotrophic yeast. In this species, activation of the $M O X$ promoter is dependent on Adrlp (Pereira and Hollenberg, 1996), a transcription factor that regulates the expression of a number of genes encoding peroxisomal enzymes (Simon et al., 1991). This finding indicates that mo- 
lecular mechanisms governing regulation by glucose may be conserved in both species.

In S. cerevisiae, the Mig1p-Ssn6p-Tup1p complex represses several genes involved in the utilization of different carbon sources (e.g. sucrose, galactose) when cells are grown in the presence of glucose $(\mathrm{Bu}$ and Schmidt, 1998; Rohde et al., 2000). When glucose is exhausted from the growth medium, the same genes need the protein kinase Snflp to be properly derepressed (Gancedo, 1998; Ostling et al., 1996). Both the Mig1p-Ssn6p-Tup1p and the Snf1 complexes are highly conserved among several species and seem to contribute, in addition to glucose regulation, to many other processes (Cassart et al., 1997; Lo et al., 2001; Yamashiro et al., 1996; Zaragoza et al., 2000). As an example, the deletion of a TUP1 homolog in Candida albicans causes failure in hypha development (Braun and Johnson, 1997).

In this study, $H$. polymorpha genes highly homologous to TUP1 and SNF1 were cloned, disrupted and analyzed for their possible conserved roles in the regulation of genes involved in $\mathrm{C}_{1}$ metabolism. The results show that mutants lacking HpTUP1 did not exhibit altered levels of $M O X$ and $D A S$ transcription when grown on methanol or glucose. On the other hand, mutants lacking HpSNF1 presented lower $M O X$ and $D A S$ induction on methanol, when compared to wild-type cells. Taken together, these results indicate that the participation of Snflp in the regulation of the major $H$. polymorpha $\mathrm{C}_{1}$ metabolism genes occurs in a Tup $1 \mathrm{p}$-independent manner, therefore implying a minor involvement of these conserved proteins in the mechanism of glucose repression of methanol metabolism.

\section{Materials and Methods}

\section{Yeast strains and growth conditions}

The $H$. polymorpha strain used to disrupt homologs of the TUP1 and SNF1 genes was isogenic to strain CBS 4732 (wild type - WT). YPD (1\% yeast extract, 2\% peptone, $2 \%$ glucose $)$ was used as rich medium. SD $(0.17 \%$ Yeast Nitrogen Base, 0.5\% ammonium sulphate) was used as synthetic medium and was supplemented with $5 \%$ glucose or $1 \%$ methanol. Cells were grown at $37^{\circ} \mathrm{C}$.

\section{Bacterial strains, plasmids and oligonucleotides}

Escherichia coli strain DH10B (Invitrogen) was used for all DNA manipulations (grown at $37^{\circ} \mathrm{C}$ in LB medium). The plasmid pF6A-kanmx4 (Wach et al., 1994) was used for construction of the disruption modules (see below). pGEM-T (Promega) and pUC18 were used for routine cloning of PCR products. The oligonucleotides used in this work are listed in Table 1 and were synthesized by Operon.

\section{Cloning of H. polymorpha TUP1 and SNF1 genes}

The cloning strategy was based on degenerated oligonucleotides. We designed degenerated primers for conserved regions of the TUP1 and SNF1 gene sequences from S. cerevisiae, Schizosaccharomyces pombe and $C$. albicans (Table 1). These primers were used to conduct PCRs, using $H$. polymorpha genomic DNA as template. Fragments containing $600 \mathrm{bp}$ and $800 \mathrm{bp}$ were amplified using primers DTup1 and DSnf1, respectively. These DNA fragments were cloned into pGEM-T (Promega) and sequenced. The DNA sequences obtained were then analyzed by Blast $\mathrm{X}$ and found to present high similarities with $C$. albicans TUP1 (4e-84) and SNF1 (5e-54). The sequences of the 5' and 3' extremities of each fragment were used to design the specific primers shown in Table 1 (Stup1F, Stup1R; Ssnf1F, Ssnf1R). Each of these primers was used in combination with T7 or SP6 custom primers to amplify cDNA fragments from a $H$. polymorpha cDNA library, constructed in our laboratory using the vector pSPORT (Invitrogen). By this procedure, the putative HpTUPI and HpSNF1 gene fragments were expanded. The predicted amino acid sequences encoded by the $H$. polymorpha TUP 1 and $S N F 1$ genes were compared with known homologs of other yeast species (see Figure 1) using the Multalin tool (www.prodes.toulouse.inra.fr/multalin/multalin.html).

\section{Disruption and screening of Hptup1 and Hpsnf1 strains}

The HpTUP1 and HpSNF1 DNA sequences obtained as described above were also used to design chimerical disruption oligonucleotides. These oligonucleotides (see Ta-

Table 1 - Primers used in this work.

\begin{tabular}{ll}
\hline Primer & Sequence \\
\hline Degenerated & \\
DSnf1.1 & 5'GGRRTTTCAATTRYRTCNGTRTCRAAGC3' \\
DSnf1.2 & 5'GCYTGNARRTGYAARTTYGCNTGRTGNGG3' \\
DTup1.1 & 5'GGGGTACCYTTCCADATNCKNGCYTTRCARTCN \\
& CC3' \\
DTup1.2 & 5' GGCTGCAGGGCNAYGARCARGAYATHTAYTC 3' \\
Disruption & \\
CdSnf1.1 & 5'TCACCATCAAGGAGATCATGGAGGACGAGT \\
& AGCTTGCCTCGTCCCCGCCGGGTC 3' \\
CdSnf1.2 & 5'GGTTGTATTTGGTTCCATTATTCGTCGACAG \\
& CAGTATAGCGACCAGC3' \\
CdTup1.1 & 5'TTTCTGGCTCAGAAGCCAGCCCAGTAAGATT \\
& TTGGAGCTCGCTCGTCCCCGCCGGGTC3' \\
CdTup1.2 & 5'CCCGACACCTCTCTTCTGGGTCATAACCGGT \\
& TCGACAGCAGTATAGCGACCAGC3' \\
Specific & \\
DasF & 5'ACTTCAACAGAGACAGGTTTG 3' \\
DasR & 5' AAATTGACAGACACAGACAGGTC 3' \\
Snf1.1 & 5' TCACCATCAAGGAGATCATGGAGG 3' \\
Snf1.2 & 5' GGTTGTATTTGGTTCCATTATTCG 3' \\
Tup1.1 & 5' CTTCGACTCAGCCAATGAAAGCG 3' \\
Tup1.2 & 5' TCTGATAACAGAGTTTCTGTGTCC 3' \\
\hline
\end{tabular}


A HpTUP1 alignment

Tup1p Candida albicans

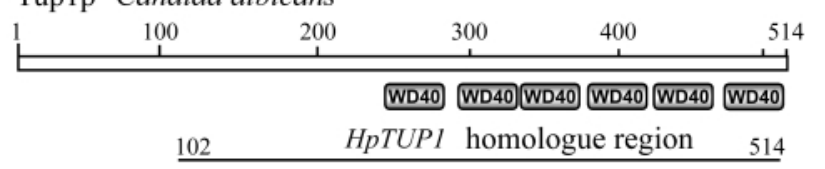

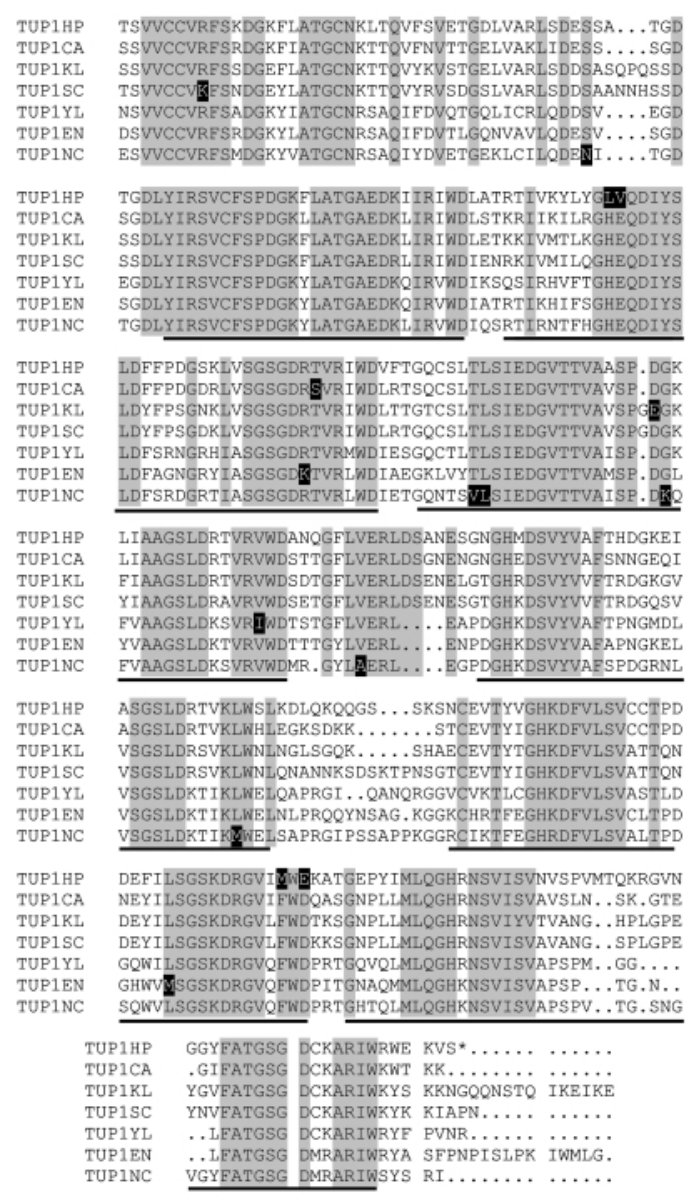

B HpSNF1 alignment

Snflp Candida albicans

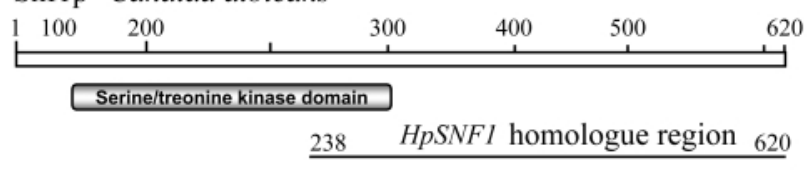

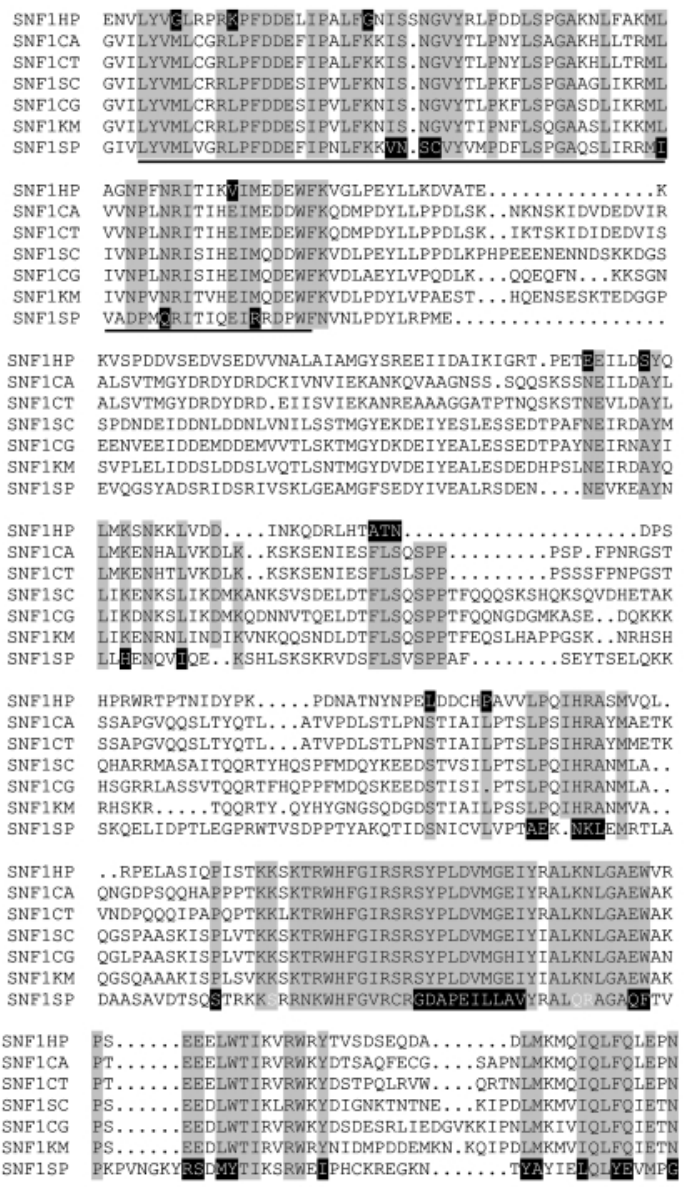

SNF1HP NYLVDEKFDGWESKSPAKSGPAEOEL, . ODSDETSSFSAYPFLHLATIRLIMELAVNSO . . SNF1CA NYLVSFKFSGWESAHGNAGTDSPQSHRQQDLDEVGSFSAYPFLHLATRLIMELAVNSQSG SNF1CT NYLVDEKFDGWEQTSDESKNDASLDYKQQDLDEVGSFSAYPFLHLATRLIMELAVNSQSG $\begin{array}{ll}\text { SNF1SC } & \text { NYLVDEKFDGWESSYGDDTTVSNISE } \ldots . . . \text { DEMSTFSAYPFLHLTTKLIMELAVNSQSN } \\ \text { SNF1CG } & \text { NYLVDEKFDGWESTYGDSTISTNMSE } . . . . \text { DEMSTESAYPFLHLTTKLIMELAVNSOGN }\end{array}$ SNF1KM SNF1S

Figure 1 - Identification of $\mathrm{Hp} T U P 1$ and $\mathrm{HpSNF1}$ gene fragments. Alignments of the predicted HpTup1p (A) and HpSnflp (B) proteins with other known homologs: HP - Hansenula polymorpha, CA - Candida albicans, CG - Candida glabrata, CT - Candida tropicalis, EM - Emericella nidulans, KL - Kluyveromyces lactis, NC - Neurospora crassa, SC - Saccharomyces cerevisiae, SP - Schizosaccharomyces pombe, YL - Yarrowia lipolytica. The known conserved domains identified in C. albicans proteins are schematically shown on top of the alignments (see text for details). Black boxes: single differences between species; gray boxes: highly conserved regions; underlined amino acids: essential functional domains. Alignments were done with the Multalin tool (www.prodes.toulouse.inra.fr/multalin/multalin.html), and the DNA sequences were deposited in the NCBI GenBank with the accession numbers: HpTUP1 - AY145087 and HpSNF1 - AY155202.

ble 1 and Figure 2) present $\sim 30 \mathrm{bp}$ of the genes to be disrupted in their 5' extremities; the 3' extremities are composed of $\sim 25$ bp complementary to the Multiple Cloning Site of the pF6A plasmid in which the kanmx4 disruption module was integrated (Wach et al., 1994). Specific TUP1 and SNF1 kanmx4 modules were constructed with these primers (CDTup1.1+CDTup1.2 and CDSnf1.1+CDSnf1.2, respectively) by standard PCR using the pF6A-kanmx4 plasmid as template. Either of these linear disruption modules bears sequences, at both the 5' and the 3' ends, which are homologous to TUP1 and SNF1 genes. These were used to transform $H$. polymorpha WT electro-competent cells (Cregg and Russell, 1998). The kanmx4 module confers resistance to the drug G418, used for preliminary screening. 


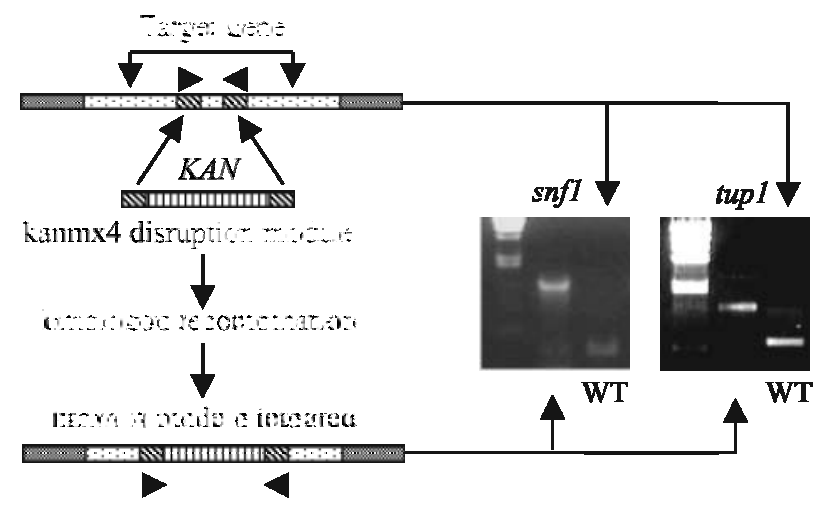

Figure 2 - Disruption strategy and screening of $H$. polymorpha tupl and snfl mutants. The specific kanmx4 disruption modules were constructed by PCR using chimeric oligonucleotides (see Materials and Methods for details). Screening for positive mutants growing in G418 was done by PCR, using specific primers for the HpTUP1 and HpSNF1 genes. These primers (STup1.1, STup1.2; SSnf1.1, SSnf1.2) amplify respectively 500 bp and $300 \mathrm{bp}$ of the wild-type genomic copies of each gene. Mutants in which the genes were efficiently disrupted present a single $1.5 \mathrm{~kb}$ band as PCR product.

Positive transformants growing in the presence of G418 (Amersham) were confirmed by colony PCR and also by PCR with genomic DNAs, using the specific primers STup1.1+STup1.2; SSnf1.1+SSnf1.2 (Table 1).

\section{PCR conditions}

All PCRs were performed in a final volume of $50 \mu \mathrm{L}$, using kits (Promega) and following instructions provided by the manufacturer. The reactions were carried out in a 9700 thermocycler (Applied Biosystems) using the following programs: i) for fragment amplification $-96{ }^{\circ} \mathrm{C}$ for 4 min, followed by 30 cycles at $94{ }^{\circ} \mathrm{C}$ for $30 \mathrm{~s}, 40{ }^{\circ} \mathrm{C}$ (degenerated primers) or $50^{\circ} \mathrm{C}$ (specific primers) for $30 \mathrm{~s}$, and $72^{\circ} \mathrm{C}$ for $1 \mathrm{~min}$; ii) for construction of the disruption modules $-96^{\circ} \mathrm{C}$ for $4 \mathrm{~min}$, followed by 30 cycles: $94^{\circ} \mathrm{C}$ for $30 \mathrm{~s}$, $70{ }^{\circ} \mathrm{C}$ for $30 \mathrm{~s}$, and $72{ }^{\circ} \mathrm{C}$ for $1.5 \mathrm{~min}$.

\section{Induction experiments and Northern Blotting}

Cells were grown overnight in $100 \mathrm{~mL}$ YPD shaking at $280 \mathrm{rpm}$, harvested (centrifuged at $5000 \mathrm{rpm}, 10 \mathrm{~min}$ ) and inoculated in the appropriate medium at an $\mathrm{OD}_{600}=2.0$. After $6 \mathrm{~h}$ of growth, cells were collected for RNA extraction. Total RNA was prepared by the hot acid phenol method (Ausubel et al., 1998). Samples were resolved by formaldehyde gel electrophoresis, blotted onto a positively charged nylon membrane (Hybond $\mathrm{N}^{+}$- Amersham Pharmacia) and fixed following standard protocols. The probes used were the following DNA fragments (numbers refer to position relative to each ORF start codon): $M O X$ - a $2.3 \mathrm{~kb} E c o R V$ fragment ( +21 to +2323$), C A T-\mathrm{a} 1.7 \mathrm{~kb}$ $E c o \mathrm{RI} / E c o \mathrm{RV}$ fragment $(+172$ to +1695$)$, and $D A S$ - a $1.0 \mathrm{~kb}(+197 /+1196)$ PCR fragment obtained with the primers Dasf and Dasr. All probes were labeled by random primer extension with $\alpha-{ }_{-}^{32} \mathrm{P}[\mathrm{dATP}]$ (Amersham
Pharmacia). Hybridization was carried out at $42^{\circ} \mathrm{C}$ following standard protocols (Ausubel et al., 1998). rRNA bands in agarose/formaldehyde gels stained with ethidium bromide prior to blotting were used as internal loading control.

\section{Growth characterization}

The different strains were grown to log-phase in YPD, harvested and resuspended in the appropriate media (indicated in Results) to an $\mathrm{OD}_{600}=0.01$. Aliquots were collected each hour for $24 \mathrm{~h}$ and the $\mathrm{A}_{600}$ was measured. The results presented are the average of three independent experiments.

\section{Patch growth assays}

The assays were performed as described elsewhere (Demasi et al., 2001; Verdoucq et al., 1999).

\section{Results}

\section{Identification of H. polymorpha TUP1 and SNF1 homologs}

H. polymorpha DNA fragments were obtained by PCR, using degenerated primers for important regions of the TUP1 and SNF1 genes (Table 1 and Figure 1). The putative HpTUP1 fragment encompassed six WD repeats (Figure 1), a typical motif of this protein family, which is involved in protein-protein interaction and signalling (Smith et al., 1999). The putative HpSNF1 fragment bears a region with high similarity to other related proteins, including part of the serine/threonine domain which is present in all SNF1-like kinases (Hanks and Hunter, 1995) (Figure 1). Fragments of both genes presented the highest similarities with homologs from the Candida genera, which is phylogenetically close to Hansenula. Sequence comparison analyses led us to the conclusion that the DNA fragments obtained encompass the most important functional regions of H. polymorpha TUP1 and SNF1 genes.

\section{Construction of TUP1 and SNF1 H. polymorpha mutants by PCR}

The HpTUP1 and HpSNF1 fragments were used to construct disruption modules, as described in Materials and Methods. $H$. polymorpha wild-type cells were transformed and positive colonies growing on G418 were selected. About 150 transformants for each gene were screened for the presence of the disruption module by PCR amplification using specific primers for the HpTUP1 and HpSNF1 gene fragments. Figure 2 depicts the disruption strategy and the PCR products of correct integrations, observed for 7\% of the transformants, in comparison to amplification of the wild-type fragments. Growth abilities of tupl and snfl cells on plates containing G418 were also re-checked in comparison to wild-type cells (not shown). 


\section{Expression of $\mathrm{C}_{1}$ metabolism genes in tup1 and snf 1 mutants}

It has been established in several yeast species that Tup1p plays a key role in repressing genes involved in the utilization of a number of carbon sources in response to the availability of glucose in a growth medium ( $\mathrm{Bu}$ and Schmidt, 1998; Rohde et al., 2000). Conversely, it is also well known that Snflp accounts for relieving the repression caused by the Mig1p-Ssn6p-Tup1p complex at different promoters (Gancedo, 1998; Ostling et al., 1996). Since the major $H$. polymorpha $\mathrm{C}_{1}$ metabolism genes are severely repressed by glucose, it was hypothesized that Tuplp and Snflp homologous proteins might also be involved in the mechanism of glucose repression/derepression of these genes. To address this issue, the expression of the genes $M O X, D A S$ and $C A T$ was analyzed by Northern Blot in wild-type, tup 1 and snfl cells grown on glucose or methanol.

In tup 1 cells grown on either glucose or methanol, the transcription levels of the three genes were similar to those observed in the wild type (Figure 3). This indicates that the repression mediated by glucose on $H$. polymorpha MOX, $D A S$ and $C A T$ promoters is Tuplp-independent. Interestingly, $s n f 1$ cells presented a significant reduction in the levels of $M O X$ and $D A S$ transcription in cells grown on methanol (Figure 3), suggesting that $S N F 1$ might be needed for activated transcription of these genes under this condition. These results indicate that Snflp action in the derepression of the genes $M O X$ and $D A S$ happens through a different molecular mechanism (e.g., different from relieving the Mig1p-Ssn6p-Tup1p complex repression at promoters). On the other hand, the levels of CAT transcription remained unaffected in snfl cells under all conditions tested (Figure 3), which indicates that the glucose repression/derepression mechanism acting on this promoter is also independent of Snflp.

\section{Effects of tup1 and snf1 disruptions on glucose and methanol utilization}

In $S$. cerevisiae, disruption of the genes TUP1 or $S N F 1$ lead also to several pleiotropic phenotypes, in addition to transcriptional regulation mediated by glucose. For instance, a TUP1 disruption caused cell flocculation (Lipke and Hull-Pillsbury, 1984), whereas a SNF1 disruption led to a general slow growth (Schuller and Entian, 1987). Thus, to examine whether $H$. polymorpha tup 1 and snfl cells presented altered growth abilities on glucose or methanol, or showed any additional phenotype, we monitored the growth rates of cells from each strain in liquid media (Figure 4B). Surprisingly, no difference was observed among the wild-type, tup 1 and snfl cells grown in either glucoseor methanol-containing media. Moreover, we could not detect any tupl or snfl pleiotropic phenotype under the conditions tested. To confirm this observation, we carried out patch growth assays (Demasi et al., 2001; Verdoucq et al.,

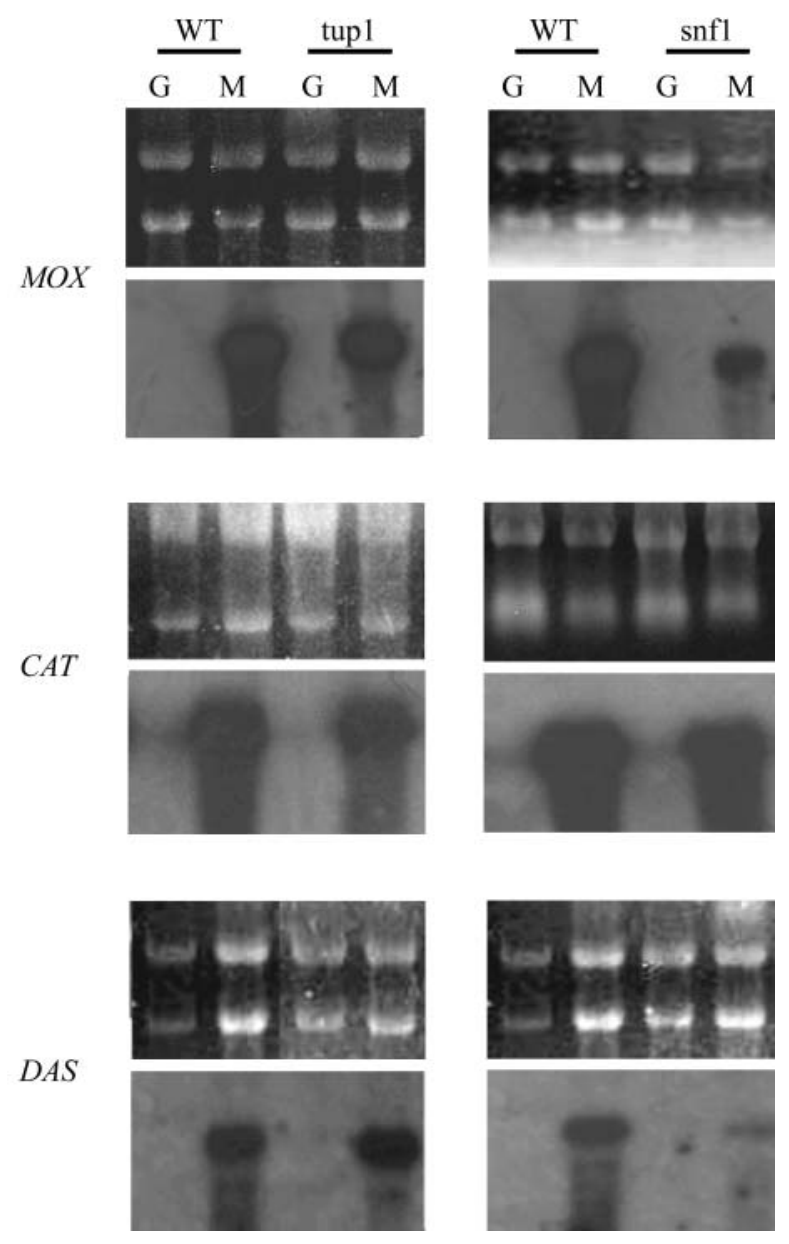

Figure 3 - Expression of $M O X, C A T$ and $D A S$ in WT, tupl and snfl cells. Northern blotting of samples collected after shifting cells from repressing (cells grown overnight in glucose $5 \%$ - time 0 ) to derepressing conditions (methanol 1\%) for $6 \mathrm{~h}: \mathrm{G}$ - glucose; $\mathrm{M}$ - methanol. rRNA bands of samples used in each filter are shown in agarose-formaldehyde gels stained with ethidium bromide prior to blotting. The probes used are described in Materials and Methods.

1999) on plates containing glucose or methanol as carbon sources (Figure 4A). Once again, we did not observe differences in either glucose or methanol utilization among the three strains. Taken together, these results indicate that, contrarily to S. cerevisiae, tup 1 or $\operatorname{snfl}$ disruptions failed to lead to any direct effect in the carbon utilization pathways of $H$. polymorpha.

\section{Discussion}

The transcriptional regulation of $H$. polymorpha $\mathrm{C}_{1}$ metabolism promoters, especially the $M O X$ promoter, has been intensively studied because of their potential in mediating industrial heterologous protein expression. The most important feature of these promoters is the strong glucose repression mechanism that functions when glucose is available in the growth medium, which makes this sugar useless as a carbon source for industrial fermentation of $H$. polymorpha. Thus, understanding the precise molecular 

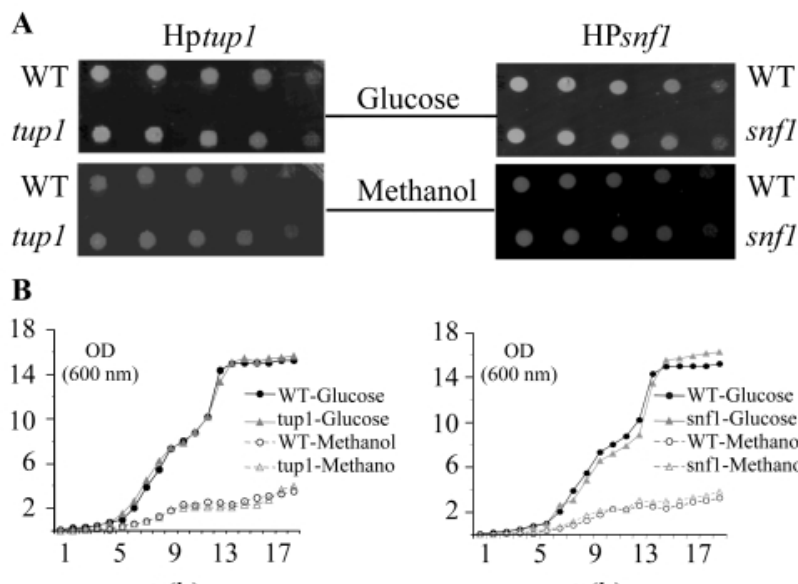

$\mathrm{t}(\mathrm{h})$

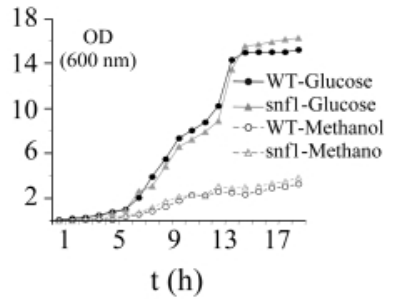

Figure 4 - Effects of tup1 and snfl deletions on growth on glucose and methanol. A: Patch growth assays were performed with wild-type, swi2 and swi3 cells in agar plates containing $5 \%$ glucose or $1 \%$ methanol (Verdoucq et al., 1999; Demasi et al., 2001). Plates were photographed after $48 \mathrm{~h}$ of incubation at $37{ }^{\circ} \mathrm{C}$. B: Growth rates of WT, tupl and snfl strains on liquid media containing $5 \%$ glucose or $1 \%$ methanol were determined by monitoring growth for up to $24 \mathrm{~h}$. The results are the average of three independent experiments.

mechanisms governing glucose repression of $\mathrm{C}_{1}$ metabolism promoters may be useful to expand their expression profiles and allow the utilization of these promoters under conditions where they are presently ineffective. For these reasons, we investigated possible contributions of the conserved $H$. polymorpha TUP1 and SNF1 genes in the glucose repression mechanism.

TUP1 mutations eliminate or reduce glucose repression of many $S$. cerevisiae promoters. In addition, they induce several other phenotypes, like flocculation, failure to sporulate, and sterility of MAT- $\alpha$ cells (Williams and Trumbly, 1990). Surprisingly, no apparently abnormal phenotype was observed in $H$. polymorpha tupl cells. These cells were indistinguishable from the wild-type by microscopic analysis, and no variations in growth behavior or in expression of the $\mathrm{C}_{1}$ metabolism genes were observed. It is important to note that, although the deletion achieved does not encompass the complete ORF, the removed region bears the WD40 repeats, which are essential and sufficient for TUP1 repressing function in $S$. cerevisiae (Sprague et al., 2000; Williams and Trumbly, 1990). These results were unexpected, since clear effects of TUP1 mutations have been demonstrated in other yeast species closer to $H$. polymorpha than $S$. cerevisiae. For example, Candida albicans TUP1, which works in a complex similar to that identified is $S$. cerevisiae, is involved in general regulation of metabolism, cellular morphogenesis and stress response (Murad et al., 2001). Although TUP1 is not essential in this species, its deletion led to female sterility, reduced growth rates and failure to turn on filamentous growth (Braun and Johnson, 1997; Yamashiro et al., 1996).
With regard to proper $S N F 1$ function in $S$. cerevisiae, it is required for appropriate derepression of several glucose-repressible genes, such as $S U C 2$ (encoding invertase), GAL1 (encoding galactokinase) and $A D H 2$ (encoding alcohol dehydrogenase 2) (Abrams et al., 1986; Denis and Audino, 1991; Flick and Johnston, 1990). The snf1 mutation leads to pleiotropic effects, such as a petite-like phenotype and a generally slow growth, which gives the mutant cells a "sick" appearance (Carlson et al., 1981). One of the main roles of Snflp in $S$. cerevisiae is to relieve repression mediated by the Mig1p-Ssn6p-Tup1p complex, by phosphorylating the Mig1p protein and releasing the complex from promoters (Ostling and Ronne, 1998). Additionally, Snflp is also involved in the operation of transcription factors like Adr1p (Young et al., 2002), and possibly other still unidentified factors (Gancedo, 1998). For example, disruption of the Candida glabrata SNF1 homolog resulted in the loss of the ability to utilize trehalose, indicating that even in an organism with a limited carbon utilization spectrum, the regulatory mechanism governing catabolite repression is preserved (Petter and Kwon-Chung, 1996).

Consistent with the possibility of playing a role in derepression in $H$. polymorpha, the deletion of SNF1 led to a significant reduction of the $M O X$ and $D A S$ expression in cells growing in methanol. This effect seems to be specific for some genes, since $C A T$ expression remained unaffected by the deletion. These results reinforce the view that $M O X$ and $D A S$ are tightly co-regulated, and that possibly Snflp plays a role in their regulatory circuits. However, this role may not be due to the inactivation of the Mig1p-Ssn6pTup1p complex, as has been reported for several $S$. cerevisiae genes (Gancedo, 1998). As described above, HpTUP1 does not seem to repress either $M O X$ or $D A S$ expression. Probably, HpSNF1 exerts its effect by interacting with a putative Adr1p-like factor that is believed to regulate MOX (Pereira and Hollenberg, 1996). In S. cerevisiae, several genes, including some that encode peroxisomal proteins, are regulated by both factors (Denis and Audino, 1991; Navarro and Igual, 1994; Simon et al., 1992). Moreover, ScSnflp has been recently demonstrated to promote binding of Adr1p to chromatin (Young et al., 2002). Taken together, these facts indicate that both factors (Snflp and Adr1p) act in conjunction in the regulation of some genes, a situation that might be conserved in other yeast species.

However, despite the reduction in $M O X$ and $D A S$ expression, deletion of HpSNF1 did not lead to any obvious external phenotype, in contrast to what has been observed in C. albicans (Petter et al., 1997) and C. tropicalis (Kanai et al., 1999), species which are phylogenetically close to $H$. polymorpha. Another interesting observation was that the snfl growth rate on methanol-containing media was indistinguishable from wild-type cells, indicating that the reduction in $M O X$ expression was not sufficient to create a bottleneck in peroxisomal methanol metabolism. 
In summary, our work indicates that, in contrast to the observations made for other yeast species, TUP1 and SNF1 do not play essential roles in carbon source regulation in $H$. polymorpha. Nonetheless, Snflp may participate in the activation of genes repressed by glucose, but at least in the case of the genes $M O X$ and $D A S$, its mechanism of action differs from counteracting the repression mediated by the Tup1p-containing complex.

\section{Acknowledgments}

We thank Thiago C. Lopes for supplying the pF6Akanmx4 plasmid; Anderson F. Cunha, Ana P. D. Demasi, Carla C. J. Maria, Lyndel W. Meinhardt and Sérgio F. Reis for critically reading the manuscript. This work was supported by grants from Fundação de Amparo à Pesquisa do Estado de São Paulo (FAPESP - Brazil) to M.A.O. and G.A.G.P.

\section{References}

Abrams E, Neigeborn L and Carlson M (1986) Molecular analysis of SNF2 and SNF5, genes required for expression of glucose-repressible genes in Saccharomyces cerevisiae. Mol Cell Biol 6:3643-3651.

Ausubel FM, Brent R, Kingston RE, Moore DD, Seidman JG, Smith AJ and Struhl K (1998) Current Protocols in Molecular Biology, John Wiley \& Son, New York, USA.

Braun BR and Johnson AD (1997) Control of filament formation in Candida albicans by the transcriptional repressor TUP1. Science 277:105-109.

$\mathrm{Bu} \mathrm{Y}$ and Schmidt MC (1998) Identification of cis-acting elements in the SUC2 promoter of Saccharomyces cerevisiae required for activation of transcription. Nucleic Acids Res 26:1002-1009.

Carlson M, Osmond BC and Botstein D (1981) Mutants of yeast defective in sucrose utilization. Genetics 98:25-40.

Cassart JP, Ostling J, Ronne H and Vandenhaute J (1997) Comparative analysis in three fungi reveals structurally and functionally conserved regions in the Mig1 repressor. Mol Gen Genet 255:9-18.

Cregg JM and Russell KA (1998) Transformation. Methods Mol Biol 103:27-39.

Demasi AP, Pereira GA and Netto LE (2001) Cytosolic thioredoxin peroxidase I is essential for the antioxidant defense of yeast with dysfunctional mitochondria. FEBS Lett 509:430-434.

Denis CL and Audino DC (1991) The CCR1 (SNF1) and SCH9 protein kinases act independently of cAMP-dependent protein kinase and the transcriptional activator ADR1 in controlling yeast $\mathrm{ADH} 2$ expression. Mol Gen Genet 229:395-399.

Flick JS and Johnston M (1990) Two systems of glucose repression of the GAL1 promoter in Saccharomyces cerevisiae. Mol Cell Biol 10:4757-4769.

Gancedo JM (1998) Yeast carbon catabolite repression. Microbiol Mol Biol Rev 62, 334-361.

Gellissen, G. (2000). Heterologous protein production in methylotrophic yeasts. Appl Microbiol Biotechnol 54:741-750.
Genu V, Godecke S, Hollenberg CP and Pereira GG (2003) The Hansenula polymorpha MOX gene presents two alternative transcription start points differentially utilized and sensitive to respiratory activity. Eur J Biochem 270:2467-2475.

Giuseppin ML, van Eijk HM and Bes BCM (1998) Molecular regulation of methanol oxidase in continuous culture of Hansenula polymorpha. Biotechnol Bioeng 194:577-583.

Godecke S, Eckart M, Janowicz ZA and Hollenberg CP (1994) Identification of sequences responsible for transcriptional regulation of the strongly expressed methanol oxidaseencoding gene in Hansenula polymorpha. Gene 139:35-42.

Hanks SK and Hunter T (1995) Protein kinases 6. The eukaryotic protein kinase superfamily: kinase (catalytic) domain structure and classification. Faseb J 9:576-596.

Janowicz ZA, Eckart MR, Drewke C, Roggenkamp RO, Hollenberg CP, Maat J, Ledeboer AM, Visser C and Verrips CT (1985) Cloning and characterization of the DAS gene encoding the major methanol assimilatory enzyme from the methylotrophic yeast Hansenula polymorpha. Nucleic Acids Res 13:3043-3062.

Kanai T, Ogawa K, Ueda M and Tanaka A (1999) Expression of the SNF1 gene from candida tropicalis is required for growth on various carbon sources, including glucose. Arch Microbiol 172:256-263.

Lipke PN and Hull-Pillsbury C (1984) Flocculation of Saccharomyces cerevisiae tup1 mutants. J Bacteriol 159:797-799.

Lo WS, Duggan L, Tolga Emre NC, Belotserkovskya R, Lane WS, Shiekhattar R and Berger SL (2001) Snfl-a histone kinase that works in concert with the histone acetyltransferase Gcn5 to regulate transcription. Science 293:11421146.

Murad AM, d'Enfert C, Gaillardin C, Tournu H, Tekaia F, Talibi D, Marechal D, Marchais V, Cottin J and Brown AJ (2001) Transcript profiling in Candida albicans reveals new cellular functions for the transcriptional repressors CaTup1, CaMig1 and CaNrg1. Mol Microbiol 42:981-993.

Navarro B and Igual JC (1994) ADR1 and SNF1 mediate different mechanisms in transcriptional regulation of yeast POT1 gene. Biochem Biophys Res Commun 202:960-966.

Ostling J, Carlberg M and Ronne H (1996) Functional domains in the Mig1 repressor. Mol Cell Biol 16:753-761.

Ostling J and Ronne H (1998) Negative control of the Mig1p repressor by Snflp-dependent phosphorylation in the absence of glucose. Eur J Biochem 252:162-168.

Pereira GG and Hollenberg CP (1996) Conserved regulation of the Hansenula polymorpha MOX promoter in Saccharomyces cerevisiae reveals insights in the transcriptional activation by Adr1p. Eur J Biochem 238:181-191.

Petter R, Chang YC and Kwon-Chung KJ (1997) A gene homologous to Saccharomyces cerevisiae SNF1 appears to be essential for the viability of Candida albicans. Infect Immun 65:4909-4917.

Petter R and Kwon-Chung KJ (1996) Disruption of the SNF1 gene abolishes trehalose utilization in the pathogenic yeast Candida glabrata. Infect Immun 64:5269-5273.

Roggenkamp R, Janowicz Z, Stanikowski B and Hollenberg CP (1984) Biosynthesis and regulation of the peroxisomal methanol oxidase from the methylotrophic yeast Hansenula polymorpha. Mol Gen Genet 194:489-493. 
Rohde JR, Trinh J and Sadowski I (2000) Multiple signals regulate GAL transcription in yeast. Mol Cell Biol 20:38803886.

Schuller HJ and Entian KD (1987) Isolation and expression analysis of two yeast regulatory genes involved in the derepression of glucose-repressible enzymes. Mol Gen Genet 209:66-373.

Simon M, Adam G, Rapatz W, Spevak W and Ruis H (1991) The Saccharomyces cerevisiae ADR1 gene is a positive regulator of transcription of genes encoding peroxisomal proteins. Mol Cell Biol 11:699-704.

Simon M, Binder M, Adam G, Hartig A and Ruis H (1992) Control of peroxisome proliferation in Saccharomyces cerevisiae by ADR1, SNF1 (CAT1, CCR1) and SNF4 (CAT3). Yeast 8:303-309.

Smith TF, Gaitatzes C, Saxena K and Neer EJ (1999) The WD repeat: a common architecture for diverse functions. Trends Biochem Sci 24:181-185.

Sprague ER, Redd MJ, Johnson AD and Wolberger C (2000) Structure of the C-terminal domain of Tup1, a corepressor of transcription in yeast. Embo J 19:3016-3027.

van Dijk R, Faber KN, Kiel JA, Veenhuis M and van der Klei I (2000) The methylotrophic yeast Hansenula polymorpha: a versatile cell factory. Enzyme Microb Technol 26:793-800.
Veenhuis M, Sulter G, van der Klei I and Harder W (1989) Evidence for functional heterogeneity among microbodies in yeasts. Arch Microbiol 151:105-110.

Veenhuis M, Van Dijken JP and Harder W (1983) The significance of peroxisomes in the metabolism of one-carbon compounds in yeasts. Adv Microb Physiol 24:1-82.

Verdoucq L, Vignols F, Jacquot JP, Chartier Y and Meyer Y (1999) In vivo characterization of a thioredoxin $h$ target protein defines a new peroxiredoxin family. J Biol Chem 274:19714-19722.

Wach A, Brachat A, Pohlmann R and Philippsen P (1994) New heterologous modules for classical or PCR-based gene disruptions in Saccharomyces cerevisiae. Yeast 10:1793-1808.

Williams FE and Trumbly RJ (1990) Characterization of TUP1, a mediator of glucose repression in Saccharomyces cerevisiae. Mol Cell Biol 10:6500-6511.

Yamashiro CT, Ebbole DJ, Lee BU, Brown RE, Bourland C, Madi L and Yanofsky C (1996) Characterization of rco-1 of Neurospora crassa, a pleiotropic gene affecting growth and development that encodes a homolog of Tup1 of Saccharomyces cerevisiae. Mol Cell Biol 16:6218-6228.

Young ET, Kacherovsky N and Van Riper K (2002) Snf1 protein kinase regulates Adr1 binding to chromatin but not transcription activation. J Biol Chem 277:38095-38103.

Zaragoza O, Rodriguez C and Gancedo C (2000) Isolation of the MIG1 gene from Candida albicans and effects of its disruption on catabolite repression. J Bacteriol 182:320-326.

Editor: Sérgio Olavo Pinto da Costa 